\title{
MEDIDAS SOCIOEDUCATIVAS: CARTAS AO REINADO DO SABER
}

\author{
Gislei Domingas Romanzini Lazzarotto ${ }^{1}$ \\ Universidade Federal do Rio Grande do Sul, Porto Alegre-RS, Brasil
}

\begin{abstract}
RESUMO. O estudo problematiza a experiência desenvolvida na defensoria interdisciplinar de adolescentes em conflito com a lei num programa de extensão acadêmica da Univewrsidade Federal do Rio Grande do Sul, no contexto de políticas públicas brasileiras. A metodologia do estudo consiste em analisar as narrativas sobre o trabalho da equipe de defensoria interdisciplinar discutindo as experiências ali vivenciadas com um olhar crítico sobre as práticas desenvolvidas no atendimento de adolescentes que cumprem medida socioeducativa por terem cometido ato infracional. A análise conceitual é orientada pelo diálogo com o filósofo Michel Foucault, especial em seu texto "La vie des hommes infâmes", mapeando as relações de poder e saber que regulam as práticas institucionais e visam ao controle social dos indivíduos. A análise possibilita uma reflexão sobre as ligações que são estabelecidas entre os saberes do direito, da psicologia e da pedagogia, produzindo práticas que tendem a regular e prescrever a vida de adolescentes no contexto de atendimento socioeducativo, numa perspectiva de judicialização da vida contemporânea.
\end{abstract}

Palavras-chave: Adolescente em conflito com a lei; medida socioeducativa; psicologia social.

\section{SOCIO-EDUCATIONAL MEASURES: LETTERS TO THE REIGN OF KNOWLEDGE}

ABSTRACT. This study discusses the experience developed in interdisciplinary advocacy for adolescents in conflict with law in an academic extension program in the context of Brazilian public policy, at the Federal University of Rio Grande do Sul. The study methodology analyzes narratives about the work of the interdisciplinary advocacy team, aiming to discuss the experiences that show a critical look over the practices developed with adolescents who are under social-educational measures, prescribed due to misdemeanors. The conceptual analysis is guided by the dialogue with Michel Foucault's texts, especially the one entitled "La vie des hommes infâmes", mapping the relations of power and knowledge that regulate the institutional practices and social control of individuals. This analysis enables a reflection on the links that are established among the knowledge of law, psychology and pedagogy, producing practices that tend to regulate and prescribe the life of adolescents in the context of social-educational measures, from the perspective of judicialization of contemporary life.

Keywords: Teenager in conflict with the law; socioeducational measure; social psychology.

\section{MEDIDAS SOCIO-EDUCATIVAS: CARTAS AL REINO DEL SABER}

RESUMEN. El estudio analiza la experiencia desarrollada en la defensoría interdisciplinaria de adolescentes en conflicto con la ley en un programa de extensión académica, en el contexto de las políticas públicas brasileñas, en la Universidad Federal do Rio Grande do Sul. La metodología del estudio analiza las narrativas de trabajo del equipo de la defensoría interdisciplinaria con el fin de discutir las experiencias que evidencian una mirada crítica a las prácticas desarrolladas en la atención a los adolescentes que cumplen una medida socio-educativa debido a haber cometido un delito. El análisis conceptual se orienta a través del diálogo con el autor Michel Foucault, especialmente su texto "La vie des hommes infâmes", mapeando las relaciones de poder y saber que regulan las prácticas institucionales y que buscan el control social de los individuos. El análisis permite una reflexión sobre los vínculos que se establecen entre el conocimiento del derecho, de la psicología y de la pedagogía, produciendo prácticas que tienden a regular y prescribir la vida de los adolescentes en el contexto de la atención socio-educativa, en una perspectiva de la judicialización de la vida contemporánea.

Palabras-clave: Adolescente en conflito con la ley; medida socio-educativa; psicologia social.

1 Endereço para correspondência: Rua Visconde do Herval, 915/803, Bairro Menino Deus, CEP 90.130-151, Porto Alegre-RS, Brasil. E-mail: gislei.ufrgs@gmail.com. 
Nossa discussão aborda as problematizações elaboradas no contexto de ação do Programa Interdepartamental de Práticas com Adolescentes e Jovens em Conflito com a Lei - PIPA - desenvolvido pela Universidade Federal do Rio Grande do Sul UFRGS. Este programa é composto por ações interdisciplinares que atendem adolescentes em medida socioeducativa através de uma equipe constituída de integrantes do Programa de Prestação de Serviço à Comunidade da Faculdade de Educação, do Grupo Estação Psi, vinculado ao Instituto de Psicologia, e do G10 Grupo do Serviço de Assessoria Jurídica SAJU, da Faculdade de Direito. A experiência de extensão em atividades de oficina, acompanhamento juvenil e assessoria jurídica com o público adolescente acontece no contexto de práticas das políticas públicas, conforme diretrizes previstas no Estatuto da Criança e do Adolescente - ECA (1990).

As medidas socioeducativas são aplicáveis na situação de ato infracional cometido por adolescentes que, nos termos da lei, estejam faixa etária dos doze até os dezoitos anos incompletos. O Estatuto da Criança e do Adolescente (1990) passa a ser o documento norteador da política pública da infância e adolescência, orientado pela Doutrina de Proteção Integral. Esta doutrina afirma os direitos infanto-juvenis com respeito a sua condição peculiar de pessoa em desenvolvimento, devendo ser assegurada a proteção por parte da família, da sociedade e do Estado, e adota uma concepção socioeducativa que alia a responsabilização pelo ato e o caráter pedagógico do Programa. Assim, a ação do Estado em relação aos atos infracionais passa a ter um caráter educativo, o qual é enunciado no termo socioeducativo.

Além das diretrizes do ECA, a Lei $n .^{\circ}$ 12.594/2012 institui o Sistema Nacional de Atendimento Socioeducativo - Sinase (2012), documento que trata de um conjunto de princípios, regras e critérios de caráter jurídico, político, pedagógico, financeiro e administrativo, envolvendo o processo de apuração do ato infracional, a execução da medida socioeducativa e os modos de gestão, avaliação e controle social.

$\mathrm{Na}$ experiência de acompanhamento de adolescentes em conflito com a lei encontramos situações nas quais a atribuição da medida vem acompanhada de um conjunto de solicitações que demarcam, exatamente, até que ponto a medida socioeducativa está associada a um modo de garantir os direitos que não foram cumpridos nas políticas que rodeavam a vida desses sujeitos. É recorrente nos defrontramos com um modo de garantir direitos que consiste em permitir o acesso desses adolescentes a um atendimento em saúde ou a um curso de profissionalização associados à permanência do adolescente na medida. Nesta perspectiva, situamos uma escuta ampliada dos enunciados que designam nossas práticas como um modo de institucionalizar e controlar, exigindo uma atenta análise das posições que ocupamos ao compormos com nossos saberes um lugar nesta forma socieducativa.

Num Estado que reconhece os direitos do cidadão, mas é organizado na tensão com um sistema econômico excludente, as forças dos movimentos que participaram da luta pela criação do Estatuto da Criança e do Adolescente (1990) e que hoje buscam constituir as formas de garantia dos direitos são confrontadas com os modos de governar que priorizam um sujeito econômico. Neste contexto, sob o olhar de nossa experiência de extensão com as medidas socioeducativas, foi elaborado o objetivo deste texto, onde buscamos problematizar a medida socioeducativa como cumprimento de uma cronologia de socioeducar que acontece no arranjo de saberes do direito, da psicologia e da pedagogia, constituindo um modo de medirsubjetivar a vida juvenil num regime de normatização.

Ao pensarmos os discursos que sustentam a nocão de socioeducação, enunciado que orienta a implantação da política de execução das medidas socioeducativas, evidenciamos a junção do discurso social ao educativo, num deslocamento e ampliação dos processos educativos da escola para compor ações diferenciadas para quem não mostre o desempenho social esperado e na forma planejada. Essas são algumas pistas a respeito das questões que produzem o desenrolar de nossa reflexão.

Nesta dinâmica social, os adolescentes em conflito com a lei vão se tornando solitários e amedrontadores gigantes no discurso produzido pelo enunciado da infração. Este gigantismo do lugar da infração no adolescente vai sendo constituído nos modos de designarmos uma determinada população adolescente brasileira. Nossa inquietude nos leva a agigantar as 
perguntas e a problematização sobre como é produzido esse discurso. Neste contexto é de perguntar: quanto de Brasil se coloca neste problema enunciado como ato infracional e de violência de adolescentes e de juventude? Em que consiste a tarefa de socioeducar? Para quem ela se dirige? Como acontecem as relações entre saber e poder nos modos de executar as medidas socioeducativas? Qual seria a medida para tal percurso? Assim, buscamos analisar que tipo de práticas estamos instituindo ao participarmos de ações que sustentam o cumprimento de uma medida socioeducativa nas políticas públicas brasileiras. Este exercício implica pensarmos como nos tornamos sujeitos de determinadas verdades que dizem da vida do outro, considerando as relações que compõem a gestão de uma medida direcionada aos adolescentes que enuncia o funcionamento da sociedade brasileira. Entre o tempo a ser cumprido e o tempo enunciado na demanda juvenil, passamos a escutar o que se diz deste adolescente e o que ele diz de si e dos lugares por onde anda, analisando as práticas, na perspectica que Foucault (2004) nos orienta, para evidenciar outros sentidos que produzem essa experiência histórica e singular do contexto contemporâneo brasileiro.

\section{DE NOSSA INTERROGAÇÃO NA ATUALIDADE BRASILEIRA}

No desenrolar de nossas práticas nos percebemos em nosso cotidiano nos questionando sobre o que fazemos no tocante à garantia de direitos de adolescentes, especialmente daqueles em medida socioeducativa. A cada crítica que coloca em xeque o Estatuto da Criança e do Adolescente (1990), tendemos a buscar um lugar de defesa, afirmando uma história de luta que ainda está acontecendo, sendo necessário ter muita prudência ao criticá-lo. Paradoxalmente, vacilamos ao ouvirmos cotidianamente, "Tem que ter gente como vocês para fazer isso." como se fizéssemos algo à parte, algo que não se quer, ou ainda, que se quer delegar ao outro para demarcar onde o sujeito de direito pode ou não ser dito e visto. Então passamos a duvidar do exercício público que busca garantir os direitos afirmados na construção da democracia brasileira através das diretrizes políticas que tratam da infância e adolescência.
Temos a sensação de que estamos em manifestação todos os dias, como se estivéssemos fora do tempo. Talvez nos dias de hoje não estejamos mais tão deslocados, pois temos a interlocução com as intrigantes e significativas manifestações nas ruas das cidades brasileiras, que eclodiram no decorrer de junho de 2013. Sabemos da natureza diferente de um e outro modo de estarmos nos posicionando: nós em atividades de formação profissional, realizadas através do acompanhamento diário de situacões de violação de direitos de adolescentes, no trabalho com diferentes instâncias de execução e gestão da política pública para fazer do Estatuto da Criança e do Adolescente (BRASIL, 1990) um exercício de vida; por outro lado, as manifestações nas ruas expopndo um conjunto de insatisfações com o modo de viver e questões ainda indecifráveis sobre o odo de fazer política em nosso país. Neste sentido, Rolnik (2013) comenta que as manifestações não surgiram do nada, mas sim de movimentos que foram sendo constituídos na vida cotidiana brasileira, como o movimento do passe livre, a resistência urbana, os movimentos dos sem-teto e os movimentos estudantis. A autora destaca que a perturbação da ordem de um país que parecia viver a prosperidade e a paz pode indicar, conforme uma de suas linhas de análise, o fato de que a garantia de direitos, alimentada nas lutas dos anos de 1970/1980, que inspiraram a Constituição Federal, tenha se "esvanecido no contexto da formação de um espécie de hibridismo de Estado, desenvolvimentista e neoliberal, com uma cultura política e um modelo político-eleitoral herdados da ditadura" (Rolnik, 2013, p. 8).

As tendências que produzem uma zona de vizinhança compreendida entre a questão em análise e esse contexto marcado por manifestacões parecem dizer respeito ao lugar das políticas públicas na sociedade brasileira e ao modo como as relações com o Estado cada vez mais são orientadas para respostas que atendam aos interesses do capital mais que à afirmação de uma vida pública condizente com os interesses da população. Cabe aqui a pergunta sobre como nossos saberes vão compondo essa trama de relações que envolve desde 0 atendimento ao adolescente até as formas de gestão, formação e participação na garantia de políticas públicas. 
Muitas vezes, por orientarmos nossas práticas do cotidiano pela afirmação da garantia de direitos à criança e ao adolescente, conforme preveem as diretrizes das políticas públicas, somos vistos como sonhadores, enquanto, na verdade, a preocupação espanta o sonho, pois somos soterrados na aceleração da engrenagem do processo jurídico judicializado e nas formas naturalizadas de tornar um adolescente um infrator. O passado de tutela, do menor, do recolhimento e da escravidão está todo aqui. Então, quem sabe uma medicação para dormir... Acordamos com o pesadelo de estarmos fazendo parte do circuito que recolhe, julga, escraviza!

Prado (2012) destaca, com base na obra $A$ Verdade e as Formações Jurídicas, de Michel Foucault (2003), que na formação histórica de procedimentos não exatamente jurídicos, a partir da captura de adolescentes infratores pelo Estado, esses procedimentos passam a ser judicializados. São procedimentos que transbordam as fronteiras do jurídico e se transversalizam pela sociedade, atuando como regulação e governo cotidiano das condutas dos indivíduos. Para o autor, tal genealogia aponta algumas condições de possibilidade para a experiência de judicialização que vivemos contemporaneamente.

Onde estaria o movimento de vislumbrar um horizonte com a experiência do presente? Como demarcar o tempo que nos faz perceber a vida que inventamos? Afinal, se o devir de um horizonte não encontra passagem, já não somos capazes de habitar o tempo na duração daquilo que possibilita a análise de nossos atos, apenas seguimos insones, ou num sono feito de pesadelos. O que produziria tamanho incômodo vivido por estudantes, professores e técnicos de uma universidade pública que se propõe a oferecer uma prática de defensoria interdisciplinar aos adolescentes ditos em conflito com a lei? De que conflito se trata?

Para prosseguirmos com essa reflexão e problematizarmos nossas práticas, optamos por permanecer com nossos questionamentos, fazendo deste movimento um modo de falar com a vida enunciada neste trabalho com adolescentes.

\section{SOBRE A FUNÇÃO DESTA ESCRITA}

A escolha por enunciar aqui o que se passa em nosso dia a dia não passa pela busca por reproduzir os registros de nosso trabalho e muito menos constituir a prova do que aqui buscamos problematizar. Narrar o que vivemos no exercício de uma extensão acadêmica é efeito de um tempo que dura em nosso corpo e se faz passagem em palavras. Por isso sua existência nesta escrita tem a função de manter o movimento de afetar e ser afetado, desnaturalizando nossas práticas. A escrita, aqui, implica em ultrapassar a experiência vivida e experimentar o que permanence solicitando análise nas narrativas da equipe, o sentido que segue em movimento para além de uma audiência, uma reunião, uma entrevista.

As análises de Deleuze (1997) a respeito do escrever permitem evidenciar o caminho metodológico que escolhemos para esta reflexão. Na obra Crítica e Clínica (1997) o autor trata de um conjunto de caminhos traçados a respeito da literatura sobre saúde, abordando obras de Lewis Carroll, Louis Wolfson, Whitman, entre outras, nas quais destaca a frágil saúde do escritor que, como escritor do mundo, inventa um povo que falta, bastardo, inferior, dominado, em devir e inacabado. Deleuze (1992) afirma que a escrita pode, por si mesma, produzir um sentimento de iminência de que algo vai acontecer ou que acaba de se passar, constituindo um agenciamento de enunciação. Neste sentido, o escrever ultrapassa o lugar de registro, pois diz respeito às circunstâncias que o produzem, e fabrica semióticas particulares de expressão que Deleuze e Guattari (1995) definem como uma política da língua que podemos percorrer aos estarmos atentos às variações da enunciação em relação ao conjunto das circunstâncias nas quais elas vão se produzindo.

Assim, escrever a experiência de nossas práticas possibilita experimentar a tensão que emerge nas novas distinções sobre o que fazemos no trajeto que a análise produz. Temos, então, uma escritora-experimentadora que atinge uma zona de vizinhança na qual já não pode distinguir-se daquilo que está se tornando, no percurso de um fazer que insiste em permanecer em nossas práticas através de discussões, escritas e incômodos de uma equipe. Este movimento não diz respeito somente a quem assume a autoria deste texto, pois este lugar é efeito de um conjunto de elementos históricos e políticos que nos posicionam ali, produzindo em nossa voz uma enunciação coletiva. Neste sentido, buscamos 
em Foucault (2004) uma noção de experiência historicamente singular, o que implica em identificarmos as relações que produzem essa prática no percurso da política pública brasileira entre saberes da psicologia, do direito e da pedagogia. A tentativa deste trabalho analítico da experiência vivida com os adolescentes em medida socioeducativa acontece na trama de linhas de análise que envolvem o histórico de como opera a política pública da criança e do adolescente no Brasil, os regimes de saberes que orientam nossos fazeres, determinando uma expectativa quanto as funções que cada disciplina deve cumprir na intervenção com o adolescente, com os demais profissionais/saberes e com o cumprimento de uma política, e o que este adolescente deve atender ao ser socioeducado (Lazzarotto \& Carvalho, 2013). O trabalho analítico, na perspectiva de Foucault (2004), implica em discutirmos nossa experiência na correlação entre os campos de saber, os sistemas de poder que regulam uma prática e as formas nas quais os indivíduos podem e devem se reconhecer como sujeitos dessa experiência.

\section{UM DIA DE 2012 - DIÁRIO DE UMA AUDIÊNCIA.}

Entre as lembranças de nosso fazer, a experiêcia de uma audiência é evidenciada. Naquele dia, a primeira audiência da tarde era do adolescente acompanhado pela nossa equipe, mas com ele chamaram mais três adolescentes, somando quatro adolescentes para serem julgados ao mesmo tempo. $O$ primeiro pensamento de quem acompanhava o adolescente era de que os quatro haviam cometido $o$ ato infracional juntos, 0 que justificaria uma audiência coletiva; mas essa suposição foi caindo por terra, pois o motivo para serem julgados juntos era que teriam a mesma sentença. Restava, então, escutar o que a juíza dizia $e$ ir se preparando para falar do acompanhamento realizado com o adolescente e de como seria dada continuidade a nosso trabalh; mas o tempo foi passando e somente ela falou. Ninguém foi ouvido. A primeira audiência finalizou e, antes que os participantes desta saíssem, entraram mais três adolescentes. Depois de estes se acomodarem, foi perguntado o nome de cada um e a juíza começou a falar. Os ouvintes, então, surpreenderam-se. Embora diante de outros adolescents, com suas respectivas e singulares vidas, a fala da juíza era a mesma da primeira audiência.

Vou fazer uma pergunta para vocês. Vocês sabem qual é a diferença entre uma pessoa e um rato? O rato é um animal que não pensa, enquanto o ser humano pode pensar. Por quê e o quê que o rato faz? Ele só come e dorme, não pensa na vida dele, ele só sabe fazer isso. E uma pessoa drogada faz a mesma coisa; só fuma, cheira, se injeta, mal come e quase não dorme. A pessoa que usa droga ela acaba virando a mesma coisa que um rato. Vocês, querem ser ratos ou homens? Eu estou vendo aqui que vocês são uns guris bons, pela cara a gente já sabe quem são. Tem outros que aparecem aqui que já sabemos que o negócio vai ser terrível, que esse não vai dar para recuperar. Mas não é o caso de vocês. Vemos que têm as mães que se preocupam e que vocês têm caras de bonzinhos. Porque agora vocês terão um novo início, poderão começar de novo. Tudo isso aqui que vocês fizeram e passaram (pega uma folha de documentação de algum dos guris) tudo que está escrito aqui vai ser apagado. Isso aqui (os documentos) não serve mais para nada (rasga o papel), estão vendo? Não haverá mais registro. Vocês saem daqui limpos como essa folha em branco (pega uma folha em branco). Vocês têm que cuidar para não encher essa folha com escritos novamente, não pode ficar assim de novo (mostra uma folha preenchida de escritos). E isso é uma responsabilidade só de vocês, não da mãe de vocês, do pai, da polícia e nem comigo, porque eu, eu não tô nem aí se vocês vão fazer alguma burrada de novo. Vocês acham que eu vou me preocupar? Não é problema meu, é problema de vocês e só de vocês. Vocês têm que sair daqui homens, e não ratos. Homem trabalha, estuda e tem responsabilidade, e vocês a partir de agora têm que ser homens. (Diário da Equipe do Programa Interdepartamental de Práticas com Adolescentes e Jovens em Conflito com a Lei - PIPA, 2012).

Não foi necessário pesquisarmos pastas e escritas de prontuários em arquivos empoeirados pelo tempo das portas fechadas. Tudo está acontecendo entre nós. A permanência dessa audiência em nossas palavras enuncia a necessidade de criar um 
regime de visibilidade em relação ao que acontece no dia a dia de um trabalho como o presente, em que vidas são tratadas como arquivos. Antes de lá constarem, esses adolescentes já são vistos e tidos como bons ou maus, caso de polícia e de medida. "Vidas de algumas linhas ou de algumas páginas, desditas e aventuras sem número, recolhidas numa mãocheia de palavras. Vidas breves, achadas a esmo em livros e documentos." (Foucault, 2002, p. 89-90). Para o autor, a força de uma vida se extinguiria quase instantaneamente, não fossem o arquivo e seus enunciados, que ultrapassam o tempo datado na sua obra para estar em nossas vidas, A Vida dos Homens Infames (Foucault, 2002). O autor considera este texto como uma "antologia de existências" (p. 90), ideia que lhe ocorreu ao ler documentos da Biblioteca Nacional, em Paris, e encontrar um registro de internamento redigido logo no início do século XVIII. Uma das leituras que refere como disparadora desta produção diz respeito ao seguinte registro:

Mathurin Milan. posto no hospital de Charenton no dia 31 de agosto de 1707:

Sua loucura sempre foi a de se esconder de sua família, de levar uma vida obscura no campo, de ter processos, de emprestar com usura e a fundo perdido, de vaguear seu pobre espírito por estradas desconhecidas, e de se acreditar capaz das maiores ocupações." (Foucault, 2002, p. 90-91).

O cansaço e a fraqueza avançam, restandonos plagiar Michel Foucault (2002) em sua obra feita da vida de homens ditos infames, pois nela encontramos a ênfase com o que o autor afirma não ser uma "recolha de retratos" (p. 96), mas "armadilhas, armas, gritos, gestos, atitudes, astúcias, intrigas, de que as palavras foram os instrumentos" (p. 96); no entanto, como já enunciamos nossa cópia, escolhemos compartilhar a análise dessa infração, uma ousadia desdobrada da noção de autoria como um achado, um roubo entre muitas vozes que habitam um autor, conforme Deleuze e Parnet (1977) nos indicam ao analisarem para que serve, afinal, uma conversa. Para nós, palavrear com esses autores, as produções de nossa equipe e a imensidade de leitores deste texto, produz uma conversa para estarmos entre sentidos em produção que se expressam no acontecimento dessas relações: um texto vivo.
Nesta direção, as narrativas de nosso trabalho com adolescentes aqui explicitadas mantêm o movimento de problematização, construindo passagens para a produção de sentido de nossas práticas. O diário da equipe que enuciamos busca o movimento de duração do que é vivido por aqueles que trabalham com estes adolescentes, compondo o exercício de relações de poder e saber na análise do que nos propomos a constituir nas formas de intervir com os adolescentes, ditos sujeitos de direito. A busca pelo texto de Michel Foucault (2002) e a sensação de o estarmos plagiando acontecem ao nos perguntamos qual o sentido de nosso saber e experimentarmos a ignorância à medida que determinadas tarefas que vão sendo instucionalizadas para nossas funções são acompanhadas de uma ordem que faz psicólogos, advogados, pedagogos,-- educadores questionarem: para quê? Ao dialogarmos com Foucault, percebemo-nos num acontecimento que ultrapassa a cronologia de nossa experiência, numa espécie de dolorosa experiência feita do encontro do saber com o poder e a ética. Nós nos instalamos no exercício de ir e vir com os conceitos e o autor para, quem sabe, assim produzirmos uma morada, um contorno enunciável de sonhos e pesadelos criados na vigília de nossas práticas.

O autor prossegue compartilhando o desenrolar de sua tarefa diante dessas existências feitas de vidas escritas com poucas linhas, mas que carregam a intensidade do exercício do poder de modo a governá-las (Foucault, 2002). Afirma ainda que não procurou reunir textos que seriam melhores que outros, ou textos para serem evidenciados por terem um valor representativo, mas que permaneceu com aqueles que desempenharam um

\begin{abstract}
... papel nesse real do qual falam, e que, em compensação, se encontram, seja qual for sua inexactidão, a sua ênfase ou sua hipocrisia, atravessados por ele: fragmentos de discurso que consigo levam fragmentos de uma realidade da qual fazem parte (Foucault, 2002, p. 96).
\end{abstract}

Essas vidas foram descritas e escritas com linhas que percorreram seus afetos $e$ expressões, compondo o jogo de forças que decidiriam seus destinos. No percurso desta análise, o autor vai situando como os dicurssos vão constituindo os mecanismos de poder que atravessaram essas vidas, pois "... tais 
existências foram efectivamente postas em risco e deitadas a perder nestas palavras." (Foucault, 2002, p. 96).

Para nossos dias, tais vidas são repletas de nomes de adolescentes que insistem em nossas letras, pois ficamos ali, no percurso do acontecer de suas experiências, em que algo pousa em nós e perdura. Então, aqui chegamos. O que nos traz para este lugar é a mão que faz do foco do olhar a grafia da intensidade de uma palavra, efeito de um lugar de saber que aqui também, nos posicionou $\mathrm{E}$ agora?

Para a sociedade brasileira, estamos diante de notícias de hoje, mas temos ciência de que ressoam no encontro com aqueles que surgiram de repente, através de dois séculos de silêncio, conforme refere Foucault (2002). São singulares vidas de hoje que poderiam ter seguido anônimas e no silêncio, mas nestas circunstâncias históricas e políticas tornam-se registros dos argumentos para diminuição da maioridade penal diante dos índices crescentes de morte de jovens no Mapa da Violência (Waiselfisz, 2011), ou ainda, são "aqueles bandidinhos de vocês", conforme escutamos em nossas andanças pela cidade.

\section{DA EXISTÊNCIA JUDICIALIZADA}

Diante de existências adolescentes, anunciadas em nossa atualidade brasileira, com suas desventuras analisadas pela produção de nossos saberes, vamos percorrendo o movimento de uma equipe que se contorce entre dispositivos de fazer ver e falar sobre e com essas vidas ditas infratoras.

Um desses adolescentes chega para realizar o cumprimento de uma medida socioeducativa na atividade de prestação de serviço à comunidade no programa da universidade, acompanhado de sua guardiã legal, responsável pela casa de acolhimento institucional onde ele está há sete anos. Gosta de esportes, pratica várias modalidades de atletismo e já ganhou prêmios nesta atividade. Participou do programa Jovem Aprendiz, trabalhando como arquivista num banco. Depois desse relato, estranhamos o fato de estar sendo medicado, sob a justificativa de que tem problemas de ansiedade; mas esse era somente o início do estranhamento - para não dizer perplexidade:

Quando questionamos sobre sua família, sua resposta quase sempre é feita de 'muito tempo'... 'muito tempo' que não vê a mãe, 'muito tempo' que o pai faleceu, 'muito tempo' que não vê o irmão. No meio da conversa repara muito nos objetos da sala, e pergunta empolgado: Vocês tem xadrez??. Pergunto se ele gosta de jogar, ele diz que sim, que aprendeu com um pessoal que dava aula na praça perto do abrigo. (Diário da Equipe do Programa Interdepartamental de Práticas com Adolescentes e Jovens em Conflito com a Lei - PIPA, 2013).

O motivo de seu encaminhamento para o cumprimento da medida socioeducativa está registrado como destruição de patrimônio público. No relato consta que ameaçou um dos educadores quanto este se recusou a permitirIhe sair ao pátio para fumar, e que deu "uns pedalaços" na porta, derterminando o registro no relatório de destruição de patrimônio. Ficamos a perguntar quem seria adolescente: Um atleta? Um aprendiz? Um arquivista? Um ansioso? Um destruidor de patrimônio público? Um possível destruídor de vidas? Um "rato" ou um "homem"?

Não bastou praticar esportes, trabalhar, jogar xadrez. Nem assim conseguiu descobrir no vislumbre dos adultos ao seu redor que poderia, ao cumprir o esperado, tornar-se um "homem". A "droga" já estava oficialmente ofertada como medicação para a ansiedade, e o conflito com o adulto oficialmente conduzido como ato infracional. Talvez ele esteja entre aqueles "guris bons" identificados pelo olhar de uma juíza, posição que torna desnecessário parar diante de qualquer integrante de um circuito institucional (casa de acolhimento - delegacia da criança e do adolescente - juizado) para indagar: estamos criando "homens" ou inventando "ratos"?

Esses percursos de vida vão sendo institucionalizados no exercício de práticas que vão dando forma a um modo de governar no exercício das políticas ditas públicas. As prescrições de como os modos de ser devem ser constituídos e controlados no desenrolar das relações de poder e saber indicam que essas vidas desempenham uma função nesta dinâmica institucional da qual passam a fazer parte. Foucault assim escreve:

Aquilo que as arranca à noite em que elas poderiam, e talvez devessem sempre, ter ficado, é o encontro com o poder: sem este choque, é indubitável que nenhuma palavra teria ficado para lembrar seu fugidio trajecto. $O$ poder que 
vigiou aquelas vidas, que as perseguiu, que, ainda que por só um instante, prestou atenção em suas queixas e ao seu leve borburinho e que as marcou com um golpe das suas garras, foi também o poder que suscitou as poucas palavras que delas nos restam: quer porque se Ihe tenham querido dirigir para denunciar, apresentar queixar, solicitar, suplicar, quer porque ele tenha pretendido intervir e que algumas palavras tenha julgado e decidido. Todas aquelas vidas que estavam destinadas a passar ao lado de todo discurso e a desaparecer sem nunca terem sido ditas, não puderam deixar traços - breves, incisivos, enigmáticos muitas vezes senão em virtude de seu contacto momentâneo com o poder. (Foucault, 202, p. 97-98).

No percurso desta reflexão podemos problematizar o que torna a soma adolescente + infração um foco do olhar de nossa sociedade para marcar seus rastros, constituindo a cada passo, a cada visão, uma relação de suspeita, tornando-o um gigante que ameaça a vida brasileira. Esses adolescentes crescem para serem visibilizados como perigosos e acionarem os dispositivos de controle, e diminuem para terem direitos assegurados e seus trajetos acolhidos como singulares exercícios de uma vida por vir.

Entre seus movimentos de crescer e diminuir podem-se encontrar também traços de seus trajetos. Eles vão e vêm nas atividades oferecidas na universidade: trazem pais, avós, irmãos e namoradas para compor nossas intervenções; terminam a medida e desaparecem; voltam para solicitar alguma orientação; não cumprem a medida e permanecem conosco em atividades guiadas por suas vontades; aparecem novamente através da notícia de que estão numa medida de privação de liberdade; voltam para contar da vida;.... São variações que tensionam o exercício de nossas relações de socioeducar, guiadas por saberes que devem ter um tempo medido entre encontros produzidos pelo que já não sabemos medir direito.

Por estarmos numa posição de quem afirma saberes, um regime de práticas vai sendo constituído e assim uma experiência se coloca em análise. Nessa análise é preciso considerar que pouco dizemos a este ou esta adolescente sobre o que dele e dela é dito, pois passamos a compor essas existências pelos enunciados.
Como destaca Foucault (2002), há aí um jogo de circunstâncias de um determinado momento histórico que atraiu sobre este indivíduo, seus equívocos e suas condutas, o olhar do poder $e$ seus mecanismos de vigilância, focando este de preferência àquele, para assegurar a norma prescrita neste ordenamento social.

$O$ sujeito de direito tem que ser direito seguindo uma norma do modo de se constituir sujeito, sendo que aqueles que enunciam o desvio, a diferença, passam a ser o foco de controle. Aparentemente os demais estariam livres, já que atendem à prescrição da norma de como se deve viver. Engodo. Ao nos localizarmos numa posição guiados pelas práticas que normatizam a vida, passamos a fazer parte desta trama de relações do exercício de poder e nesta posição ficamos amarrados, uns lá, outros aqui, para permanecermos quem somos na ordem desta sociedade.

Assim, a infâmia se faz rede de subjetivar. Os infames de nosso tempo têm uma função a cumprir nas relações de poder que fazem funcionar a sociedade. Precisam se constituir como um segmento da população que num determinado regime tenha visibilidade, para se tornar um foco exemplar para o modo de nos subjetivarmos como bons ou ruins, com mais ou menos direitos. No cotidiano de escolas e de estabelecimentos de acolhimento institucional, o crescimento do modo de tratar as relações com adolescentes como casos de polícia e de processo judicial não tem apenas uma função com este ou aquele adolescente, pois cria uma concepção social de que não temos capacidade de agir na singularidade das relações para produzir práticas próprias às circunstâncias de cada situação com as variações de modos de ser e de viver.

A formação histórica desses procedimentos não exatamente jurídicos, conforme já comentamos no diálogo com Prado (2012), vai sendo construída com os diferentes saberes, visando justificar um modo de governar as condutas através das ações do Estado, sendo que saberes como a psicologia, o direito e a pedagogia passam a compor essa regulação da vida no cotidiano dos indivíduos. A relação com as práticas judiciárias passam a ser disparadoras de uma forma de judicializar/controlar a vida, afastando-se do exercício de relações com um sujeito de direito.

Vamos encontrar no âmbito da escola, da unidade de saúde, do centro comunitário, do 
conselho tutelar outros espaços da cidade, uma tendência a priorizar desdobramentos menos coletivos e compartilhados na construção de acordos e buscas de alternativas locais para o que não atende a norma. Passamos adiante nossa responsabilidade, especialmente aos saberes especializados e/ou às instâncias jurídicas. Bem sabemos que os desviantes e diferentes não desaparecem depois de um atendimento ou de uma medida socioeducativa, portanto a questão segue nas mãos de todos.

No que se refere à psicologia, Prado (2012) discute que nossas práticas podem assumir um funcionamento que constitui uma justiça paralela. Isso ocorre à medida que nossas práticas se posicionam na função de produzir laudos, perícias e pareceres técnicos que irão subsidiar decisões de outros saberes e de sentenças judiciais. O autor mostra que há uma psicologização dos poderes modernos que torna mais sutil e mais individualizante suas formas de atuar sobre a vida do outro, destacando que a criminalização das condutas e a judicialização da vida são correlativas da patologização das condutas e da medicalização da vida.

$\mathrm{Na}$ experiência que vivemos no regime de práticas da defensoria interdisciplinar e no trabalho de extensão acadêmica que recebe demandas de adolescentes em medida socioeducativa, nós nos depararmos com o modo como nossos saberes tratam do adolescente, que é utilizado para justificar esta ou aquela ação no seu processo judicial, tensionando as relações de saber e poder produzidas entre as disciplinas envolvidas. $O$ que força o pensamento a indagar a função destes saberes nas circunstâncias de nossa intervenção é a atenção dedicada ao (des)encontro entre um modo de praticar e a abertura para acolher a expressão de adolescentes que tensionam nossas ações, num exercício que se torna enunciável à medida que desnaturalizamos nossas práticas de formação nestas áreas disciplinares.

O adolescente, ao se perceber vigiado, constrói com esses olhares seu modo de estar no mundo. Sabe o que dizer a esse ou àquele profissional, por onde andar ou não. Por vezes, inclusive, diante dos riscos vividos, percebe que Ihe resta ficar num estabelecimento de internação. Faz uma guerrilha solitária consigo para dar conta da sobrevivência. Fica a pergunta: em que ele está se transformando ao se constituir nessas relações?
A pista para prosseguirmos em nosso trabalho tem como referência as análises de Foucault (2002) a respeito de como se estabelece nosso contato com os rastros da vida desses adolescentes, o modo como percorremos alguns de seus movimentos ao percebermos a dinâmica em que passam a ser alvo das relações de poder de nossa sociedade. Eles se tornam acessíveis para nossa análise ao nos percebermos nesses jogos de poder, os quais nos posicionaram, inclusive, neste lugar de escrever. Os rastros de suas vidas passam a ser percorridos, nas posições que ocupamos, ao produzirmos as práticas com as medidas socioeducativas, em que o cansaço revela que algo acontece entre nós!

\section{UMA HISTÓRIA QUE HABITA NOSSO TEMPO}

Podemos pensar que os documentos pesquisados por Foucault (2002), que constituíram o estudo genealógico de vidas ditas infames, enunciam modos de viver que se tranversalizam numa linha do tempo, ressoando no jogo de forças do poder da e sobre a vida de nossos dias. Talvez, ao estarmos tão embrenhados nas relações que se fazem no presente, uma espécie de bruma se forme ao nosso redor, dificultando revelar o que nos acontece. Então, seguimos atentos aos processos que deram duração aos enunciados formulados nos registros do estudo formulado por Michel Foucault, pois assim vamos encontrando pistas que podem evidenciar os modos de producão de um regime de verdade e de como nossos saberes passam a constituir-se nas posições que ocupamos.

O estudo de Foucault (2002) destaca um período - em torno dos anos 1660-1760 - em que se podia notar na França uma mudança importante no mecanismo que tinha por função controlar a vida cotidiana. Em sua análise o autor evidencia a passagem do mecanismo cristão, constituído pelo uso da confissão, para um mecanismo administrativo, marcado pelo uso do registro. "É um tipo completamente diferente de relações que se estabelece entre o poder, o discurso e o quotidiano, uma maneira completamente diferente de gerir este último e de o formular. Nasce, para a vida ordinária, uma nova encenação" (Foucault, 2002, p. 112). Neste outro modo de esquadrinhar as condutas são retomados alguns procedimentos antigos, como 
a denúncia, a queixa, a inquirição, o relatório, o interrogatório. Nos arquivos do internamento da polícia dessa época estão as "lettres de cachet ou as ordens reais" (p. 112), um documento emitido em nome do rei, que sujeitava um indivíduo ao aprisionamento ou internação, em função de condutas que transgrediam a ordem social, conforme o que estava descrito no pedido que originava essa determinação. Foucault explica:

\begin{abstract}
A lettre de cachet que se entregava como a vontade expressa e pessoal do rei, de fazer encerrar um de seus súbditos fora das vias da justiça regular, não era senão a resposta a um pedido vindo de baixo. Todavia, não era concedida de pleno direito a quem a pedia: devia ser precedida de um inquérito destinado a ajuizar do bem fundado da solicitação; devia estabelecer se sim ou não tal abuso ou tal embiaguez, tal violência e tal libertinagem eram merecedores de internamento, em que condições e por quanto tempo: tarefa da polícia, que para este fim, recolhia testemunhos, delacções, e todo aquele equívoco murmúrio que turva o ambiente em volta de cada um. (Foucault, 2002, p. 113114).
\end{abstract}

O autor destaca ainda que esse sistema de ordens de prisão e internamento, embora seja um episódio breve e localizado na França, tem significativa importância na história dos mecanismos do poder. Essa importância está vinculada, em especialmente ao fato de esse sistema não ser considerado um abuso puro do próprio poder do monarca, pois cada um podia usar esse poder absoluto para si, para seus próprios fins e contra os outros, através de uma distribuição de circuitos complexos e num jogo de solicitações e respostas (Foucault, 2002). Com esse poder político, na forma do absolutismo, cada um pode tornar-se para o outro um monarca sem lei numa trama de exercício do poder no cotidiano. Para o autor, esta estratégia tornou-se uma armadilha tanto dos que se utilizavam das solicitações de ordens de prisão como do rei que as concedia. Os solicitantes foram perdendo seu espaço em função da maior presença de um poder administrativo e o monarca foi sendo menos apreciado à medida que se embrenhava entre tantas relações orientadas pelo ódio e intriga.
Foucault (2003) analisa como este modo de tratar as condutas evidenciou novos mecanismos de controle social que prosseguiram nas formas de funcionamento do Estado na sociedade. A resposta dada para uma conduta indesejável já não era uma resposta para um dano ocorrido em função da conduta do indivíduo. Foucault esclarece:
Enquanto o drama judiciário se desenrolava entre dois indivíduos, vítima e acusado, tratava-se apenas de dano que um indivíduo causava a outro. A questão era a de saber se houve dano, quem tinha razão. A partir do momento em que o soberano ou seu representante, o procurador, dizem: 'também fui lesado pelo dano', isto significa que o dano não é somente uma ofensa de um indivíduo a outro, mas também uma ofensa de um indivíduo ao Estado, ao soberano como representante do Estado; um ataque não ao indivíduo mas a própria lei do Estado. Assim, na noção de crime, a velha noção de dano ser substituída pela de infração. A infração não é um dano cometido por um indivíduo contra outro; é uma ofensa ou lesão de um indivíduo a ordem, ao Estado, à lei, à sociedade, à soberania, ao soberano. (Foucault, 2003, p 66).

A questão que nos toca neste primoroso estudo genealógico de Foucault diz respeito ao modo como a soberania política vai se inserindo no nível mais elementar do corpo social, envolvendo, conforme analisa o autor, uma microfísica de relações, como as familiares, as de vizinhança, as de interesses, de profissão e outras, mas especialmente a maneira como a vida de determinado indivíduo passou a ser dita, descrita e escrita no processo de ir sendo constituída como alvo de mecanismos de um poder político:

\footnotetext{
Nascimento, pois, de uma imensa possibilidade de discurso. É aí que, pelo menos em parte, tem a sua origem um certo saber do quotidiano e, com ele, uma grelha de inteligibilidade que o Ocidente se encarregou de assenter sobre os nossos gestos, sobre nossas maneiras de ser e de agir. (Foucault, 2002, p. 118).
}

Ao destacar a configuração de um novo mecanismo administrativo para manutenção da ordem, Foucault (2003) indica que o contexto da 
segunda metade da Idade Média assistiu à transformação de novas formas de operar a justiça, suas práticas e procedimentos judiciários, bem como as formas e condições de possibilidade do saber que envolvem o direito. Essas mudanças marcam a forma como o Mundo Ocidental vai constituir as relações jurídicas. Já não se trata de uma resposta a uma infração, mas uma forma de buscar corrigir o indivíduo no que se refere ao seu comportamento e ao possível perigo que ele representa, das virtualidades de suas atitudes, em que a penalidade busca corrigir aprisionando. Essa modalidade de penalidade "é uma ideia policial, nascida paralelamente à justiça, fora da justiça, em uma prática dos controles sociais ou em um sistema de trocas entre a demanda do grupo e o exercício do poder" (p. 99).

Entre leituras e viagens no tempo da escrita deste texto, nosso movimento pousa na reunião de equipe de extensão na universidade e na vida de Pedro. Ele passou pelo programa cumprindo a medida socioeducativa de prestação de serviços à comunidade quase quatro anos atrás. Alguns meses depois de ter cumprido sua medida, recebemos a notícia de que havia sido preso num roubo feito por um grupo de jovens, que em nossa cidade é designado de bonde. Ele já havia completado dezoito anos e foi parar no presídio. Permaneceu preso cerca de seis meses - isto há mais ou menos três anos. Ele continua mantendo contato conosco para conversar sobre a vida. Recentemente, descobriu que foi condenado a três anos e meio de prisão domiciliar. Durante a preparação de sua documentação para ingressar numa empresa, os empregadores descobriram que ele tinha uma pendência com a justiça e ele foi orientado a procurar o fórum. Lá sugeriram que se apresentasse ao sistema prisional. Pedro não foi. Achava que tudo estava resolvido em sua vida. Depois de ter saído do presídio, Pedro fez curso de manutenção, trabalhou com carteira assinada em duas empresas e agora está buscando outra atividade, porque uma oportunidade melhor estava se apresentando para sua vida. Ele nos procurou. O que fazer?

Não basta que o adolescente responda ao dano específico de sua conduta, cumprindo uma medida socioeducativa, conforme as disposições legais que estabelecem como medidas a tomar uma advertência, a prestação de serviço ou a privação de liberdade, previstas no Estatuto da
Criança e do Adolescente; ou após os 18 anos, quando ele considerado um adulto, que se atenda ao sistema prisional conforme o Código Penal Brasileiro. Ele precisa responder aos ditames das circunstâncias de um tempo histórico de que o Estado se organiza para estabelecer os modos de governar a população.

As reflexões de Prado (2012) indicam que a aplicação articulada do saber-poder contribui para sustentar as formas de controle da vida na exposição dos indivíduos a um tipo de vigilância, à medida que produzimos um conhecimento sobre as particularidades de cada um, considerando este padrão normalizante para orientar como eles devem ser vigiados. Assim, há uma necessária ligação de cada um com essa identidade que se constitui, pela ordem social, na obrigação de repetir-se como vigilante de si e vigilante da sociedade.

Aqui talvez localizemos alguns elementos que nos auxiliem na análise do que enunciamos como cansaço e incômodo no decorrer deste texto. Ao habitarmos esse intenso jogo de forças, passamos a compor, também, uma relação de necessidade. Os adolescentes com os quais trabalhamos têm uma relação de importância no âmbito dos saberes, pois justificam nossa existência a partir de um exercício que realizamos nas diferentes disciplinas. Ali nos localizamos na posição de ofertar um saber especialista, numa configuração de táticas e estratégias que aos poucos tomam o lugar desta vida para ser um jogo entre saberes e instituições. O trabalho analítico e o exercício ético nos convocam a desnaturalizar nossas práticas, pois afinal o problema é saber se podemos, dentro do regime no qual exercemos poder, "transformar em níveis microscópicos" (Foucault, 2003, p. 155) essas relações, de maneira tal que em condicões de possibilidades diferentes encontremos outras modos de exercício de poder.

Como nos alertou Foucault (2002), o poder que se exerce em nossa vida cotidiana já não é o de um monarca, mas vai sendo constituído numa rede fina, formada de forma diferenciada $e$ contínua, entre as instituições da justiça, da polícia, da medicina e da psiquiatria. Podemos incluir a psicologia, o direito, a pedagogia e um conjunto de disciplinas e instituições que, conforme o autor, formam um discurso que se apresenta com a "presunção da observação e da neutralidade. $O$ banal será analisado de acordo com a grelha eficaz mas cinzenta da 
administração, do jornalismo e da ciência; sob condição de ir procurar os seus esplendores um pouco mais longe, na literatura"(p. 122).

\section{JANEIRO DE 2013}

Numa das primeiras reuniões de janeiro somo invadidos por mais um relato sobre uma audiência. A psicóloga conta que, quando entrou na sala de audiência, solicitaram que sentasse na mesa junto das técnicas, o adolescente em medida de internação e da mãe. Foi convocada a falar sobre a possibilidade dele participar de atividades na universidade. Ela respondeu que ele havia cumprido a medida de prestação de serviço à comunidade, anteriormente, conosco. Além disso, ao ser internado no passado, seguimos acompanhando-o, já que havia escolhido seguir nas oficinas. Portanto, o programa estavar aberto para que ele seguisse nestas atividades, se assim quisesse.

A juíza perguntou se ele queria falar algo e ele disse que não. Ela insistiu. Ele ficou em silêncio. Na saída, o adolescente comentou que cansou de falar, pois não fazia a menor diferença o que ele dizia para a decisão da juíza.

Mas de que se tratava, então, a interrogação que inventava um silêncio barulhento, permanecendo em nós, na reunião, após a audiência? A juíza havia perguntado se estávamos de acordo que o adolescente fosse custodiado e algemado até a universidade.... A negativa do adolescente quando convocado a falar foi adquirindo tamanha lucidez, que o silêncio fazia nossas temporas latejarem. Nada tinha sido escutado sobre a relação daquele jovem com o espaço que havia construído com a universidade. Mas ele parecia saber, precisamente, o sentido de escutar, silenciar e falar.

Restou ouvir o carimbo nas cartas, com algemas, endereçadas ao reinado do saber.

\section{REFERÊNCIAS}

Deleuze, G. (1992). Conversações. Rio de Janeiro: 34.

Deleuze, G. (1997). Crítica e Clínica. São Paulo: 34.

Deleuze, G. \& Guattari, F. (1992). Mil Platôs: capitalismo e esquizofrenia (Vol. 2). Rio de Janeiro: 34.

Deleuze, G. \& Parnet, C. (1998). Diálogos. São Paulo: Escuta.

Foucault, M. (2002). A Vida dos Homens Infames. In M. Foucault. O que é um autor (pp. 89-128) Lisboa: Passagens.

Foucault, M. (2003). A Verdade e as Formas Jurídicas. Rio de Janeiro: NAU.

Foucault, M. (2004). O Uso dos Prazeres e as Técnicas de Si. In M. B. Motta. (Org.). Ditos e Escritos V: Ética, Sexualidade, Política (pp.190-217). Rio de Janeiro: Forense Universitária.

Lei n. 8.069, de 13 de julho de 1990. Dispõe sobre o Estatuto da Criança e do Adolescente e dá outras providências. Diário Oficial da União, Brasília, 1990.

Lei n. 12.594, de 18 de janeiro de 2012. (2012). Institui o Sistema Nacional de Atendimento Socioeducativo Sinase. Diário Oficial da União, Brasília, DF.

Lazzarotto, G. D. R. \& Caravalho, J. D. (2012). Psicologia: entre correrias, adolescentes e políticas de assistência social. In. L. R. Cruz, L. Robrigues, N. M. F. Guareschi. (Orgs.). Interlocuções entre a psicologia e a política nacional de assistência social [recurso eletrônico] (pp. 161175). Santa Cruz do Sul, RS: EDUNISC.

Prado Filho, K. (2012) Uma breve genealogia das práticas jurídicas no Ocidente. Psicologia \& Sociedade, 24(n.spe.), 104-111.

Rolnik, R. (2013). As vozes das ruas: as revoltas de junho e suas interpretações. In E. Maricato, et al. (Orgs.). Cidades Rebeldes - Passe Livre e as Manifestações que tomaram as ruas do Brasil (pp. 7-12). São Paulo: Boitempo: Carta Maior.

Waiselfisz, J. (2011). Mapa da Violência 2011. Os Jovens do Brasil. Brasília: Ministério da Justiça, Instituto Sangari.

Recebido em 11/11/2013 Aceito em 22/09/2014

Gislei Domingas Romanzini Lazzarotto: mestre em Psicologia pela Pontifícia Universidade Católica do Rio Grande do Sul, doutora em Educação pela Universidade Federal do Rio Grande do Sul, professora do Departamento de Psicologia Social e Institucional do Instituto de Psicologia da Universidade Federal do Rio Grande do Sul, Brasil. 